\title{
Research on Industrial Structure in Northern Jiangsu
}

\author{
Chen Jian \\ Huaiyin Institute of Technology \\ Jiangsu China \\ 2946446028@qq.com
}

\author{
Wang Jun \\ Huaiyin Institute of Technology \\ Jiangsu China \\ 1211692043@qq.com
}

\begin{abstract}
With the rapid economic development of Jiangsu province, the unbalanced development of regional economy is becoming more and more obvious. Under the background of present adjustment of industrial structure, this paper uses the shift share analysis method to analyze the reason that the economic development in North Jiangsu area left behind the Jiangsu provinces', and it puts forward that the Northern Jiangsu area, should develop the third industry as its main goal of economic development to narrow the economic development gap between North Jiangsu and other Jiangsu regions.
\end{abstract}

Keywords-industrial structure, shift share analysis method, the third industry, regional economic development

\section{INTRODUCTION}

Imbalance of regional economic development is one of the factors that restrict the development of China's economy; the measurement and control of regional economic differences have been an important issue in the academic field and the government's attention. Jiangsu province is a major economic Chinese province, over the years; its economy has been in the leading level of the whole country. With the rapid economic development of Jiangsu province, the unbalanced development of regional economy is becoming more and more obvious; economic development gradient feature is obvious from the south to the North, the economic gap is so large that it has a direct impact on the province's harmonious economy development, and the process of all-round well-off society. There are many reasons for the regional economic gap between the Southern, Middle, and Northern Jiangsu. Under the background of the adjustment of industrial structure, this paper will use the shift share analysis method to analyze the reason that the economic development in North Jiangsu area left behind the Jiangsu provinces', so as to narrow the economic development gap between North Jiangsu and other Jiangsu regions.

\section{SHIFT SHARE ANALYSIS}

Shift share analysis method is widely used in the mathematical analysis of the change of industrial structure and regional economic gap. It was first raised by the American scholar Donne, Perloff and others in 1960s, and has been widely applied since the early 80 s in the study of western regional economy. The basic idea of share analysis is to view the process of the change of the regional economy as a dynamic, and take its greater regional economic development as a reference, it will be the study area (this refers to the northern Jiangsu area) growth and the reference region (including Jiangsu province) growth linked comparison. The shift share analysis method considers that the regional economic growth relates to the regional share factor, the industrial structure deviation factor and the location competitive power deviation factor. The shift share analysis will divide the regional economy in the change of a period into three components , namely share component, structure deviation component and competitiveness deviation component, which indicates the reason of the development and decline of regional economy, evaluates the regional economic structure advantage and competitive ability, and finds out the area has a relative competitive advantage in industrial sector, and hence to suggest the reasonable direction for the future development of the regional economy and industrial structure adjustment principle.

The model can be expressed as the model of shift share analysis:

$$
\begin{aligned}
& \sum_{i=1}^{n} G_{i}=\sum_{i=1}^{n} N_{i}+\sum_{i=1}^{n} P_{i}+\sum_{i=1}^{n} D_{i} \\
& =\sum_{i=1}^{n} \mathrm{e}_{i 0} * \mathrm{R}+\sum_{i=1}^{n}\left(\mathrm{R}_{i}-\mathrm{R}\right) * \mathrm{e}_{\mathrm{i} 0}+\sum_{i=1}^{n} \mathrm{e}_{i 0} *\left(r_{i}-R_{i}\right) \\
& \text { Among: } \mathrm{R}=\frac{E_{t}}{E_{0}}-1, \mathrm{R}_{\mathrm{i}}=\frac{E_{\mathrm{i} t}}{E_{\mathrm{i} 0}}-1, r_{\mathrm{i}}=\frac{e_{\mathrm{i} t}}{e_{\mathrm{i} 0}}-1
\end{aligned}
$$

In the formula $e_{i o}, e_{i t}, E_{i o}, E_{i t}$ representing the GDP of of three industries in the base period and the reporting period of the study area and the reference region respectively.

\section{DATA PROCESSING}

Industrial structure is the relationship structure between industries, which reflects the relationship between the proportion of a country's industry and its changes. The industrial structure can be investigated from two aspects of quantity and quality, from the number of point of view, it refers to the industry in the national economy and the industry inside the proportion in the national economy, such as the first, the two or three industry structure; from the point of view of quality refers to the industry input-output relationship is the basic content. The study of industrial structure can bring economic benefits from the state. Reasonable performance of industrial structure for the reasonable utilization of resources; 
each industry department coordination, can provide social needs of products and services, to provide sufficient employment opportunities, to promote the application of advanced industrial technology, can achieve the best economic benefit.

This paper selected the 2010 and 2015 as the base year and the reporting period, taking Jiangsu Province as a reference region, to analyze the total change, structure deviation and competitiveness deviation status during the period of the study area of Northern Jiangsu.

The relevant data are brought into the model of the shift share analysis method:

TABLE I. INDUSTRIES IN THE NORTHERN JIANGSU PROVINCE FROM THE SHARE OF THE ANALYSIS OF THE TABLE UNIT: 100 MILLION YUAN

\begin{tabular}{c|c|c|c|c}
\hline & $\begin{array}{c}\text { The first } \\
\text { industry }\end{array}$ & $\begin{array}{c}\text { the second } \\
\text { industry }\end{array}$ & $\begin{array}{c}\text { the third } \\
\text { industry }\end{array}$ & Total \\
\hline $\mathrm{N}$ & 825.85 & 2876.54 & 2322.76 & 6025.15 \\
\hline $\mathrm{P}$ & -7.86 & -1688.17 & 2097.97 & 401.94 \\
\hline $\mathrm{D}$ & -173.54 & 1278.73 & 488.19 & 1593.38 \\
\hline $\mathrm{G}$ & 644.45 & 2467.10 & 4908.92 & 8020.47 \\
\hline G- N & -181.40 & -409.44 & 2586.16 & 1995.32 \\
\hline
\end{tabular}

\section{RESUlTS ANALYSIS}

Table $1,2 \mathrm{~N}$ is assumed to research the regional industry according to the regional economic growth rate of $\mathrm{R}$ growth should achieve growth share, the assumed growth level with real growth rate $(\mathrm{G})$ compared to, if it is higher than the actual level of growth, study area total deviation (G-N) is positive, on the other hand, is negative. It can be seen from table 1 , the first and the second industry in North Jiangsu area $(\mathrm{G}-\mathrm{N})$ of the total deviation is negative, that in the first and the second industry is lower than the actual level of growth; the third industry in North Jiangsu total deviation (G-N) is that the third industry in North Jiangsu is higher than the actual level of growth.

TABLE II. THE CITIES IN FIVE CITIES OF JIANGSU PROVINCE, THE SHARE OF THE ANALYSIS OF THE SHARE UNIT: 100 MILLION YUAN

\begin{tabular}{c|c|c|c|c|c}
\hline & Xuzhou & Lianyungang & Huai’an & Yancheng & Suqian \\
\hline $\mathrm{N}$ & 1987.23 & 806.01 & 937.55 & 1575.63 & 718.72 \\
\hline $\mathrm{P}$ & 176.45 & 47.28 & 96.65 & 74.09 & 7.46 \\
\hline $\mathrm{D}$ & 391.28 & 150.79 & 409.14 & 304.60 & 337.56 \\
\hline $\mathrm{G}$ & 2554.96 & 1004.08 & 1443.34 & 1954.32 & 1063.74 \\
\hline G- N & 567.73 & 198.07 & 505.79 & 378.69 & 345.02 \\
\hline
\end{tabular}

Table 12 , $\mathrm{P}$ which is on behalf of the study area according to the reference area I industry growth and reference according to the regional economic growth rate $\mathrm{R}$ has the difference of the amount of calculation, and it reflects the extent of the study area which is relative to the reference of regional industrial structure. When $\mathrm{P}$ is positive, the quality of the regional industrial structure is better, it can promote the regional economic growth, when the $\mathrm{P}$ is negative, it shows that the quality of the regional industrial structure is poor; it will affect the total regional economic growth. It can be seen in the data in Table 1 , the first and the second industry third industry $\mathrm{P}$ is negative, $\mathrm{P}$ is positive. It is indicating that, in the study area, the first and the second industry structure industry quality is poor, which affects the amount of regional economic growth, while the third industry industrial structure quality is good, which can promote the growth of the total regional economy.

Table 12 , D on behalf of the study area in the I industry which according to the actual growth rate of the economic growth and growth in the same industry reference region to achieve economic growth rate reflects the difference between the amount. Compared with the reference area, the study area has advantages and disadvantages in terms of the development of the I industry; if the study in the regional competitiveness of regional level is higher than the reference, $\mathrm{D}>0$ and $\mathrm{D}<0$. A component of the regional competitiveness is quite complex. In fact, competitiveness includes the effects of all factors other than industrial structure outside; its size is affected by the level of productivity, the scale of investment, and industrial policy and other factors. It can be seen from table 1, the first industry $\mathrm{D}$ is negative, the second industry and the third industry $\mathrm{D}$ is positive, that the study area has the inferior position in the development of the first industry, which has advantage in the second and three industries.

Table 2 shows the economic development of Xuzhou city is significantly faster than the other four cities, the total deviation is 56 billion 773 million yuan, which has the advantages of industrial structure growth in the amount of 17 billion 645 million yuan, an increase of 39 billion 128 million yuan due to competitive advantage. However, the growth of Xuzhou's industrial structure is positive, but its first industry, the second industry of $\mathrm{P}$ is negative, which shows that the quality of the regional industrial structure is poor. Look at the city of Suqian, the first GDP growth is far lower than the province, the total deviation is 34 billion 502 million yuan, of which the industrial structure caused by the growth of only 746 million yuan. The first and the second industry of $\mathrm{P}$ were negative, indicating the regional industrial structure quality is poor; after increasing competitive advantage to 33 billion 756 million yuan, the first industry $\mathrm{D}$ for the negative, shows the location disadvantage of primary industry.

The method is easy to be applied, and the result is simple and clear, and the calculation result is in accordance with the actual situation.

\section{CONCLUSIONS}

According to the above analysis, to develop the third industry is the main goal of economic development in Northern Jiangsu Province in the future.

1) Service industry in Northern Jiangsu soft environment is relatively backward, and education, finance and insurance, cultural and sports entertainment industry is required to carry out a full range of improvement. The service industry in the north of Jiangsu Province faces some problems - how to 
enhance the level of development of the third industry, firstly consider the optimization of the internal structure of the third industry in Northern Jiangsu area, so that each industry will achieve the maximization in a reasonable layout, investment scale and unified planning and coordinated development of various sectors, the contribution rate of social and economic development. When necessary, the government should adopt policy guidance, financial support and other related measures to coordinate. Education, health, sports, science and technology and cultural industries are solid foundation for the development of the third industry, but also to improve people's living standards, the need to vigorously should be developed these sectors in northern Jiangsu.

2) Due to the economic development of North Jiangsu long-term environment, policy constraints and other factors are facing a shortage of funds, backward production technology and talent shortage and other issues, the lack of talent is the most outstanding performance. To attract talents and keep talents very prominent, therefore, the future economic development of Northern Jiangsu area is a long-term and arduous task, which needs to develop a series of reasonable and effective training and the introduction of high-tech talent, the introduction of advanced technology or transfer policy.

3) Taking industry as the main direction, speeding up the process of new type industrialization. Strengthen industrial orientation; improve the industrial level and level. To further improve the industrial policy, high energy consumption, high pollution in the existing industry, in the low end of the industry project, strict implementation of the relevant provisions of the rectification, after rectification of all the requirements will be shut down. Pay great attention to the transformation of traditional industries with high and new technology, and vigorously develop new industries. To adjust the industrial structure by adjusting the investment structure. Focus on a number of concentrated forces with strong power, long industrial chain leading large projects, to promote the leading industry bigger and stronger, and enhance the core competitiveness of leading industries. Make full use of the abundant labor resources, the development of a relatively large space to the advantage, and strive to have a big advantage of the industrial project development into national planning, for national ministries and state-owned companies to settle in key projects. Actively undertake industrial transfer in developed areas of the Yangtze River Delta, the introduction of more large employment capacity, less resource consumption, low pollution emissions projects.

4) The total economy in Northern Jiangsu slow growth, significantly slower than the speed of economic development in Jiangsu Province, the main reason is the lack of competitiveness of the location; three industries in Jiangsu do not have advantage. The third industry contributes to the economic growth rate of the largest in North jiangsu. From the perspective of the development of Northern Jiangsu area, the proportion of industrial structure change is more optimistic, North Jiangsu high-level industrial structure level is low, but the third industry is developing rapidly, there are also single level structures, no obvious characteristics of the problem. The new trend of the actual North Jiangsu area and the current tourism development has become vigorously and has become a good choice for the development of leisure agriculture. It must proceed from the actual Subei area of emancipating the mind, changing people's traditional understanding of agriculture, to strengthen the management of the leisure agriculture guidance and training, to explore the potential for the development of leisure the enormous; the information age today, to consider the establishment of appropriate information platform for leisure agriculture operators, so as to provide information, the brand will also promote the development of leisure agriculture.

5) Optimization of supply structure. The supply structure refers to a certain price conditions as a factor of production capital, labor, technology and natural resources in the national economy can supply the proportion of Industry Association and the supply relationship linking the supply structure, including capital (capital structure). As an investment structure of supply, labor supply structure, technology supply structure and resource endowment. Natural condition and resource supply structure, etc.. Industrial structure optimization is to make structural adjustment to these factors, the adjustment of investment structure, the adjustment of educational structure, the adjustment of scientific and technological structure, etc.

6) Optimization of demand structure. The demand structure refers to the government and enterprises under the condition of a certain income level, family or individual can bear on the industrial demand for products or services as well as the proportion of demand for bond industry association. It includes the government (public) demand structure, demand structure, family demand structure or individual demand structure, and the proportion of these needs, it also includes the intermediate (product) demand structure, demand structure and final products, intermediate products and final products demand proportion; as well as the investment structure, demand factors the structure of consumption, and the proportion of consumption and investment etc.. Industrial structure optimization is also a structural adjustment of these factors.

7) The authority of the government has a strong mobilization of economic resources, able to focus on investment, in a short period of time to make certain key industries to build up. But, if the government regulation mechanism of excessive use or be inopportune or inappropriate its inherent limitations, will be completely unmasked. To promote industrial structure can realize horizontal and vertical evolution according to the inherent self regulating power of economic operation itself. In the condition of market economy, the equal share of the resources to form different benefits in different industries, contributed to the industrial transfer and allocation of resources to the high efficiency and high productivity, so as to promote the optimization of industrial structure. But the practice of evolution of industrial structure of the world and that, optimize the market mechanism on the change of industrial structure is a limitation, including blindness, regulation failure, the bottleneck industry barriers to entry, the market information is incomplete, even light industrial structure etc.. Based on the above analysis, the optimization of the industrial structure can not be pure consciously or spontaneously, but only spontaneously and consciously double adjustment process, efficiency and market regulation mechanism in the allocation of resources is much higher than the plan adjustment mechanism. In the clear market 
allocation of resources, adjust the structure of the main channel at the same time, it is necessary for the government to formulate a reasonable and predictable industrial structure policy, in order to avoid the blindness of investment behavior, planning departments and encourage priority development needs the assistance of the recession department, determine the dominant industry, basic industry and strategic industry development order more, the use of economic instruments, in strengthening the government supervision and guidance functions at the same time, pay attention to the loss of efficiency and reduce government intervention, improve the overall quality of economic benefits and economic structure.

Of course, we can also use the shift to share analysis method to further analysis, the industry classification in detail, step by step, find out the advantages and disadvantages of specific industries, such as can be subdivided into the first industry, farming, forestry, animal husbandry, sideline and fishery shift share analysis, calculate the industrial structure and competitive advantages and disadvantages. May be further planting again continue to breakdown etc.

\section{REFERENCES}

[1] Huang Bingnan, Li Wujun. Study on the industrial structure of the central region based on the shift share analysis [J]. Economic latitude and longitude, 2010 (06): 25-29. (In Chinese)

[2] Li Jianlei et al. Application of shift share method in the analysis of industrial competitiveness of 11 cities in Hebei province [J]. Journal of Hebei University of Technology School of adult education, 2005 (03): 24-28. (In Chinese)

[3] Liu Yanping. The shift share analysis of regional economic development in Jiangxi province [J]. Science and Technology Plaza, 2006, (03): 19-20. (In Chinese)

[4] Zhang Huiru, Guo Aijun. Analysis of the effect of industrial structure on economic growth in Northwest China based on shift share analysis method [J]. reform and strategy, 2009, (01): 137-139. (In Chinese)

[5] Lei Xiong. Evaluation of the competitiveness of China's regional service industry: Based on the provincial level data. Graduate School of the Chinese Academy of Social Sciences, 2013. (In Chinese)

[6] Du Hui. Study on regional coordinated development of modern service industry in Jiangsu province. Master thesis, Southeast University, 2013. (In Chinese) 